\title{
Teoria transfeminista para el análisis de la violencia machista y la reconstrucción no-violenta del tejido social en el México contemporáneo ${ }^{1}$
}

\author{
Sayak Valencia Triana ${ }^{2}$ \\ Colegio de la Frontera, Tijuana, México ${ }^{3}$ \\ mvalencia@colef.mx
}

Recibido: 26 de agosto de 2013

Aceptado: 21 de enero de 2014

\footnotetext{
El presente artículo de reflexión se enmarca dentro del proyecto de investigación "Todo lo sólido se edifica sobre sangre: masculinidades, derechos humanos y violencia en Tijuana", el cual me encuentro desarrollando actualmente como parte de mi trabajo de investigación en el Colegio de la Frontera Norte. No cuenta con financiación externa.

2 Doctora Europea en Filosofia, Teoría y Crítica Feminista de la Universidad Complutense de Madrid.

3 Investigadora titular.
}

Documento accesible en línea desde la siguiente dirección: http://revistas.javeriana.edu.co

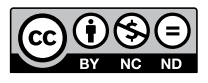




\title{
Teoria transfeminista para el análisis de la violencia machista y la reconstrucción no-violenta del tejido social en el México contemporáneo
}

\section{Resumen}

Partimos de la perspectiva transfeminista, entendiéndola como una articulación tanto del pensamiento como de resistencia social que es capaz de integrar la movilidad entre géneros, corporalidades y sexualidades con los supuestos de las luchas feministas, a fin de construir alianzas con las masculinidades no hegemónicas, para crear una organización reticular irreductible a la oposición entre géneros. Hacemos una breve genealogia de lo que se entiende por transfeminismos en distintos contextos, para después responder a las preguntas: ¿Qué tipo de sujetos y prácticas crea la reinterpretación machista del neoliberalismo extremo y cuáles son sus consecuencias sociales más evidentes en México?, ¿Cómo puede el transfeminismo re direccionar y proponer otros modelos para la creación de sujetos que no estén emparentados con la distopía del capitalismo gore, ni con la masculinidad hegemónica, ni con el hiperconsumismo neoliberalista?

Palabras clave: transfeminismo; disidencia; capitalismo gore; subjetividad endriaga; descolonialismo

\section{Transfeminist theory for the analysis of male violence and the nonviolent reconstruction of the social fabric in contemporary Mexico}

\begin{abstract}
We start from the transfeminist perspective which is understood as an articulation of both thought and social resistance that is able to integrate mobility between genders, corporalities and sexualities with the assumptions of feminist struggles to build alliances with non-hegemonic masculinities in order to create an reticulated organization implacable to the opposition between genders. We create a brief genealogy of what is meant by transfeminisms in different contexts for answering the questions: What kind of subjects and practices does the extreme sexist reinterpretation of neoliberalism create and what are its most evident social implications in Mexico?, how can transfeminism redirect and propose other models to create individuals who are not related to the dystopia of gore capitalism, nor hegemonic masculinity, or the neoliberal hyper-consumerism?

Keywords: transfeminism; dissent; capitalismo gore (gore capitalism); subjetividad endriaga (endriaga subjectivity); decolonialism
\end{abstract}

\section{Teoria transfeminista na análise da violência machista e a reconstrução não-violenta do tecido social no México contemporâneo}

\section{Resumo}

Partimos da perspectiva transfeminista entendida como articulação tanto de pensamento como de resistência social que é capaz de integrar a mobilidade entre gêneros, corporalidades e sexualidades com os supostos das lutas feministas, a fim de construir parcerias com as masculinidades não hegemônicas, para criar uma organização reticular irredutivel à oposição entre gêneros. Fazemos breve genealogia do que é entendido como transfeminismos em diferentes contextos, para depois responder às perguntas: ¿Que tipo de sujeitos e práticas está criando a reinterpretação machista do neoliberalismo extremo e quais suas consequências sociais mais evidentes no México?, ¿Como o transfeminismo pode redirecionar e propor outros modelos para a criação de sujeitos que não estiver emparentados com a distopia do capitalismo gore, nem com a masculinidade hegemónica, nem com o hiperconsumismo neoliberalista?

Palavras-chave: transfeminismo; dissidência; capitalismo gore; subjetividade endriaga; descolonialismo 
Es esencial que las feministas confrontemos nuestro miedo y la resistencia de unas hacia las otras, porque sin esto, nosotras no sobreviviremos. El verdadero poder, como tú y yo lo sabemos, es colectivo. Yo no puedo soportar tenerte miedo, ni tú a mí. Si para ello se requiere un choque de cabezas, hagámoslo. Esta refinada timidez nos está matando. [E]l movimiento feminista debe ser un movimiento de sobrevivientes, un movimiento con futuro.

Cherrie Moraga. (1988). La Güera

\section{Breve genealogia de los transfeminismos}

El término transfeminismo tiene distintos significados y varias genealogías. En el contexto estadounidense la invención del término se le atribuye a Diana Courvant, que lo utilizó por primera vez en 1992 durante un evento en la Universidad de Yale. En ese mismo contexto, Diana Courvant y Emi Koyama lanzaron una página web en el año 2000 llamada trasfeminism.org, creada para difundir el Transfeminism Anthology Projet, que tenía como objetivo introducir el término transfeminismo en la academia, así como encontrar y conectar a personas que estuvieran trabajando sobre él o sobre temas afines a este, con el fin de editar una antología al respecto. El término también ha sido usado por Robert Hill (2002), que lo define como la incorporación del discurso transgénero al discurso feminista.

Sin embargo, el transfeminismo que abordaremos en esta reflexión es el surgido a partir del año 2008 por medio de redes feministas de intercambio transnacional y que pueden ubicarse en el Estado español, aunque no exclusivamente, ya que está atravesado por la práctica y el discurso de distintas voces y corporalidades migrantes que quedaron plasmadas en distintas jornadas, seminarios, coloquios, manifestaciones, etc., realizados con continuidad desde el año 2008 hasta la fecha, en diversos países de habla hispana, siendo México uno de ellos ${ }^{4}$.

Otros países latinoamericanos que han generado y dado seguimiento a debates sobre transfeminismo son: Argentina, Bolivia, Chile, Colombia, Ecuador y Perú. Una muestra de ello se puede consultar en: Revista Ramón, núm. 99. Abril 2010. Buenos Aires, Argentina. Dossier "Micropoliticas Cuir: Transmariconizando el Sur". Editores invitados: Fernando Davis y Miguel A. López. Textos de Silvia Delfino, Flavio Rapisardi, Elizabeth Vásquez, Fernanda Carbajal, Beatriz Preciado, Inti Guerrero, Mujeres Públicas, Giuseppe Campuzano, Miguel A. López, Pablo León de la Barra, Felipe Rivas San Martin, Elisa Fuenzalida, María Galindo / Mujeres Creando y Víctor Manuel Rodríguez. http://es.scribd.com/doc/31922861/ramon-99-revista-ramona-de-argentina 
El transfeminismo, como herramienta epistemológica no se desliga del feminismo ni se propone como la superación de este sino como una red que es capaz de abrir espacios y campos discursivos a todas aquellas prácticas y sujetos de la contemporaneidad y del devenir minoritario que no habian sido considerados de manera directa por el feminismo blanco e institucional. De igual forma, teje lazos con la memoria histórica y reconoce la herencia aportada por los movimientos feministas integrados por las minorias raciales, sexuales, económicas y migrantes al mismo tiempo que se nutre de ellos, tanto discursiva como políticamente. Desde esta perspectiva, en la genealogía del transfeminismo se pueden dibujar cuatro lineas interseccionales:

1. Los feminismos de color del tercermundo y del tercermundo estadounidense $\mathrm{e}^{5}$.

2. La disidencia sexual y su desplazamiento geopolítico y epistémico hacia el sur: del queer al cuir'.

3. El movimiento por la des-patologización de las identidades trans (Stop Trans Pathologization) y el movimiento pro-puta, a favor de la des-estigmatización y legalización del trabajo sexual.

4. Los devenires minoritarios por diversidad funcional, las migraciones y la precarización económica.

Bajo estas transversales, el transfeminismo hace un llamado a proponer actualizaciones teórico-prácticas sobre la realidad y la condición de las mujeres dentro de esta. Sin embargo, este llamado no se reduce a los cuerpos legibles como mujeres sino que incluye a las distintas corporalidades y disidencias criticas, siendo requisito indispensable que tomen en cuenta las circunstancias económicas específicas de los sujetos dentro del precariado (laboral y existencial) internacional.

5 Integrado por las feministas chicanas, afroamericanas, nativo americanas, asiático americanas y sus luchas poscoloniales.

6 La variación cuir, es la derivación fonética/españolizada/desviada/impropia que busca afirmarse y relocalizarse, por medio de la reapropiación del estigma de hablar con acento que pesa sobre las hablas castellanas y las coloca en una posición subalterna/defectuosa frente a la pronunciación correcta, (con acento anglófono), del término queer. Cuir representa una des familiarización (ostranienie) del término, es decir, una des automatización de la mirada lectora. Cuir registra la inflexión geopolítica hacia el sur y desde las periferias en contrapunto a la epistemología colonial y a la historiografia anglo-americana. Es necesario aclarar también que cuir no es un sinónimo de homosexual y que no basta con ser homosexual para formar parte del movimiento cuir, ya que este es un movimiento de autocrítica que puede incluir a aquellos que mantengan practicas heterosexuales pero que disientan de los sistemas de dominación emparentados con la producción capitalista que marginaliza a todos los que han devenido minoritarios por razón de género, clase, etnia, nacionalidad, diversidad funcional, etc. 
Las y los sujetos del transfeminismo pueden entenderse como una suerte de multitudes queer/cuir que a través de la materialización performativa de las variaciones del género y la sexualidad, logran desarrollar agenciamientos g-locales. Un ejemplo de ello es Eli Vázquez, del Proyecto Trans en Quito, Ecuador, quien a través de un activismo de base enraizado en una critica descolonial, hace Usos Alternativos del Derecho y ha logrado infiltrar una perspectiva humanizada sobre lo trans en el imaginario cotidiano, así como algunas propuestas de ley para demandar derechos colectivos y garantías individuales para el colectivo trans e intersex en el Ecuador.

La tarea de estas multitudes queer/cuir es desarrollar categorías y ejecutar prácticas que no busquen asimilarse a los sistemas de representación impuestos por la hegemonía capitalista del sistema heteropatriarcal/ clasista/ racista. Además de inventar otras formas de acción que reconfiguren la posición del sur como un posicionamiento crítico y no solo como un emplazamiento geopolítico. Otro ejemplo de este tipo de transfeminismo es el trabajo de performance de Nadia Granados "La Fulminante", artista colombiana que se reapropia de la imagen de "latina sexy y ardiente" -que se vende asiduamente en el imaginario cultural contemporáneo (un remanente de la construcción de las mujeres racializadas durante la colonia) - y lo hace mestizo con un lenguaje político y erótico que emplea para hablarnos de temas como la disputa por la autogestión del cuerpo de las mujeres, el sistema de salud, la doble moral, el desplazamiento forzado y el poder en Colombia. Tanto Vázquez como Granados reactivan el carácter autocrítico y anti-dogmático de los diversos movimientos feministas y descolonialistas.

Dentro de estos marcos, el transfeminismo de impronta sudaca/ euraca/norteca ${ }^{7}$, no se reduce solamente a la incorporación del discurso trans al feminismo sino que puede entenderse como un movimiento migrante y relacional, así como la contestación desobediente a los sistemas de representación y represión dominantes, incluyendo una crítica directa al dogmatismo profesado por cierto feminismo institucional.

Dicha confrontación del dogmatismo estandarizante de los cuerpos, los afectos y los deseos se da por medio de una reformulación de

\footnotetext{
Dichos disfemismos enuncian el devenir sur globalizado, es decir, una proliferación de sures en todo el orbe. Lo cual brinda un espacio de alianza posible a través de la enunciación compartida del sur everywere, que se caracteriza por el devenir minoritario/migrante y la tercermundización del primer mundo.
} 
las representaciones y la puesta en circulación de otras taxonomías para nombrar el mundo. Así como la creación de políticas disidentes de la visualidad que dan visibilidad a los movimientos trans-marikaputa-bollo-mestizx-migrante-precarix, y al mismo tiempo denuncian las consecuencias fácticas de la violencia exacerbada -alimentada por el machismo, el autoritarismo, el clasismo y la homofobia- vinculadas con el capitalismo gore.

Ahora bien, después de esta breve genealogía pasaremos a la segunda parte de este artículo que busca responder las preguntas:

1. ¿Qué tipo de sujetos y prácticas crea la reinterpretación machista del neoliberalismo extremo y cuáles son sus consecuencias sociales más evidentes en México?

2. ¿Cómo puede el transfeminismo redireccionar y proponer otros modelos para la creación de sujetos que no estén emparentados con la distopía del capitalismo gore, ni con la masculinidad hegemónica, ni con el hiperconsumismo neoliberalista?

Para responder a estas preguntas consideramos pertinente mencionar tres temas que se enlazan con la necesidad de visibilizar la distopía machista en México y la urgencia de construir/visibilizar masculinidades desobedientes ante la hegemonía del género en nuestro país. Estos temas son:

1. El desmoronamiento del concepto de Estado-Nación dada la falta de perspectiva de los gobiernos, quienes desde la época posrevolucionaria han puesto todo su empeño en la construcción de una democracia-meramente discursiva-, pensando en esta como en una panacea. Es decir, no han sido críticos con el discurso del proyecto de la modernidad/colonialidad ni han sabido llevar a cabo una práctica geopolíticamente pertinente para el contexto mexicano. En este sentido, la reproducción acrítica de los discursos de progreso y ascensión social-que se fundan en una axiología anglo-euro céntrica-colonialista- tendrá influencia en el fracaso del Estado como proyecto emancipador, puesto que refuerza la relación de poder marcada por la diferencia colonial y cuya impronta ha sido forjadora de las demandas de la masculinidad hegemónica o tradicional ${ }^{8}$ y redistribuidas cotidianamente a los varones mexicanos de manera biopolítica por el Estado y la sociedad.

8 Somos conscientes de que los modelos de masculinidad y feminidad son contextuales y se adaptan, para sobrevivir, a los contextos históricos y a las transformaciones económicas de las sociedades. 
2. Las crisis económicas que han sufrido consecutivamente los espacios tercermundizados. Nos referimos a la desestructuración económica que ha venido padeciendo México a partir de los años 70 , donde las politicas de modernización proclamadas por el gobierno dejaron claramente desprotegido al campo, agudizándose así las migraciones de este a la ciudad y sobre todo, las migraciones hacia los Estados Unidos. Así, se inició en consecuencia una reconfiguración en el concepto de trabajo que décadas después (con el advenimiento de la globalización) derivaría en la creación e institución de una nueva clase social: la clase criminal, como motor económico del país y que en este trabajo denominamos subjetividad endriaga y que también tendrá consecuencias en las demandas de género, sobre todo las que vinculan la legitimidad masculina con el poder adquisitivo.

3. El bombardeo de los medios de comunicación, (con especial énfasis la televisión) los cuales reproducen cotidianamente estereotipos de género y representaciones de mujeres, indígenas, homosexuales y diversos funcionales en posición de inferioridad. De igual manera, se naturaliza la violencia criminal por medio de su sobre-representación, al proclamarla indirectamente como la llave para alcanzar el éxito económico.

Mencionado lo anterior, nos referiremos al primer punto y haremos una breve revisión histórica de la implicación que tiene el concepto de macho en la construcción de la identidad nacional en Latinoamérica ${ }^{9}$ $\mathrm{y}$, con especial ahínco, en México. Dicha implantación ha sido revisada, en primera instancia, por Oscar Lewis (Lewis, 1959; 1961), quien sitúa los términos macho y machismo en las décadas de 1940 y $1950^{10}$ para hacer referencia a "hombres de la clase obrera latinoamericana

9 Es cierto que Latinoamérica no es un territorio homogéneo. Sin embargo, algo que pervive dentro de la diversidad geopolitica y cultural es la división binaria de género que, si bien es cierto que tiene distintos grados de intensidad y de aplicación, también es cierto que los dispositivos de propagación del sexismo siguen siendo parte de la violencia sistémica de la mayoría de estos territorios y de muchos otros alrededor del orbe.

${ }_{10}$ A este respecto se nos puede argumentar que durante décadas recientes se han dado cambios en la masculinidad como consecuencia de una transición social (Montesinos, 2004) donde se tiende hacia la equidad de género. Sin embargo, esta argumentación sigue inscrita en un perspectiva continuista con las lógicas de la modernidad/colonialidad donde el género se construye bajo una lógica lineal y binaria. Ahora bien, estamos de acuerdo que las maneras en que el machismo se explicita hoy en día conforman un abanico complejo que se sostiene y legitima por medio de las coreografias sociales que reproducen y rearticulan la violencia sistémica, la simbólica y la situacional. Por tanto, los efectos del machismo siguen siendo atroces, aunque sus rostros se hayan multiplicado y espectralizado o aunque el machismo se haya vuelto light y el sexismo se haya vuelto hipster. 
y de la capas pobres en los barrios populares urbanos, sobre todo de México y de América Central" (Zapata, 2001, p. 237).

A este respecto, Carlos Monsiváis escribió que el término macho se expande en México después de las luchas revolucionarias como signo de identidad vinculada a las clases campesinas y obreras. Así, en la incipiente configuración de la Nación mexicana, el macho vino a ser una superlativación del concepto de hombre que más tarde se naturalizaria artificialmente como una herencia social nacional, traspasando los límites entre las clases. Por tal, la figura del macho ya no se circunscribiría solamente a las clases subalternas sino que se transformaría en un paradigma de género común a todos los varones mexicanos, prescribiendo como valores asociados a la masculinidad verdadera: "la indiferencia ante el peligro, el menosprecio de las virtudes femeninas y la afirmación de la autoridad en cualquier nivel" (Monsiváis, 1981). Es importante subrayar que en el contexto mexicano las construcciones de género están íntimamente relacionadas con la construcción del Estado.

Por ello, aprovechando la coyuntura contextual del México contemporáneo en cuanto al desmoronamiento del Estado mexicano intensificada por la clase criminal, consideramos indispensable visibilizar la conexión entre ambas organizaciones con respecto al género: las dos posiciones detentan una perspectiva común en la que se defiende y alaba el mantenimiento de una masculinidad violenta emparentada a la construcción de lo nacional. Así, todo argumento a favor de erradicar la violencia criminal debe tener en cuenta que ésta es uno de los valores estructurales en la axiologia heteropatriarcal y por tanto, que las estrategias para combatirla deben hacer énfasis en un análisis crítico de la construcción del género (masculino) en México.

Así, se vuelve necesario poner a circular una conciencia crítica respecto a la violencia del género ${ }^{11}$, donde la ciudadanía tenga noticia de que los efectos distópicos y cotidianos del derramamiento de sangre en el país no se deben únicamente a las pugnas entre grupos criminales, sino también a la obediencia ciega, profesada socialmente, hacia las demandas de la masculinidad hegemónica (Connell, 2010), (re)producidas

${ }^{11}$ Considera, al igual que otras transfeministas que el género mismo es la violencia, que las normas de masculinidad y feminidad, tal y como las conocemos, producen violencia, ya que se basan en órdenes y contraordenes, las cuales a su vez producen frustración y muy raras veces alivio. De la violencia del género y su imposición en los cuerpos sexuados y los privilegios o anti-privilegios que esta sexuación otorga en la sociedad, se desprende lo que comúnmente (gracias a las reivindicaciones y luchas feministas) se conoce como violencia de género o violencia machista. 
por las instituciones: el Estado, la iglesia, la mass media, la familia, la economia, etc., e impuestas sobre los varones.

En la misma línea de pensamiento, es necesario visibilizar socialmente que el mantenimiento de una masculinidad violenta emparentada a la construcción de lo nacional tiene implicaciones políticas, económicas y sociales que cobran en la actualidad un alto número de vidas humanas, dada la lógica machista del desafio y de la lucha por el poder y que, de mantenerse, legitimará a la clase criminal como sujetos de pleno derecho en la ejecución de la violencia como una de las principales consignas a cumplir bajo las demandas de la masculinidad hegemónica y el machismo nacional.

La deconstrucción del machismo es urgente en el contexto mexicano actual dado que el fenómeno del narcotráfico y la violencia explícita como herramientas de necro-empoderamiento ${ }^{12}$ obedecen y encarnan, de forma exacerbada, una amalgama entre las demandas de la masculinidad hegemónica y las demandas del capitalismo global contemporáneo.

De esta manera, pasamos al segundo punto que se refiere a las crisis económicas acontecidas de forma acumulativa en Latinoamérica y a la reciente crisis mundial cuyo centro de colapso se ubica en los Estados Unidos -y cuya repercusión se percibe de manera directa en la economía mexicana dada la cercanía geográfica entre los países y la gran dependencia económica que México mantiene con los Estados Unidos-. Estas crisis económicas acumulativas en México han supuesto otro tipo de crisis: la crisis del modelo tradicional de masculinidad emparentada con papel de macho proveedor.

La incorporación de las mujeres al mercado de trabajo durante la década de 1950 puede verse como un parte aguas y una fractura del modelo de la masculinidad emparentada exclusivamente a la proveeduria. Lo cual, ha desembocado en un miedo masculino generalizado: la desvirilización por causa del desempleo. Dicho miedo se ha intensificado a partir de las décadas de 1970 y 1980 a causa de las crisis y restructuraciones económicas que ahora conocemos como globalización o posfordismo.

\footnotetext{
12 Denominamos necro-empoderamiento a los procesos que transforman contextos y/o situaciones de vulnerabilidad y/o subalternidad en posibilidad de acción y auto-poder, revirtiendo así las jerarquias de opresión pero que los reconfiguran desde prácticas distópicas para hacerse con el poder y obtener a través de este enriquecimiento ilícito y autoafirmación perversa (Valencia, 2010).
} 
En este sentido, con el advenimiento de la globalización de la economía mundial y sus consecuencias de precariedad laboral y existencial, volvieron a tomar fuerza las formas ilícitas de enriquecimiento. Surgiendo de esta manera lo que en mi trabajo denomino subjetividad endriaga y que se caracteriza por construir modelos de aspiraciones de vida y masculinidad ${ }^{13}$. Modelos cuya encarnación es deseable a fin de participar de la legitimidad del neoliberalismo más radical, literal y exacerbado que denominamos Capitalismo Gore.

Es pertinente definir las características, tanto de los sujetos endriagos como del Capitalismo Gore para después visibilizar a través de esto la radicalización distópica que ha traído consigo en el contexto mexicano, el entramado entre masculinidad hegemónica, neoliberalismo globalizado y violencia, lo cual hace urgente una revisión y propuesta de otras masculinidades que puedan desvincularse de dicho entramado que ha devenido de la glorificación y naturalización del machismo proclamado por el Estado, que ha pasado de ser un Estado-Nación, que utiliza las tecnologías del género para garantizar la (re)producción y la confirmación de las identidades genéricas, a una Narco-Nación que utiliza la tecnología de la violencia y su especialización, como herramientas de necro-empoderamiento y enriquecimiento, las cuales traen como consecuencia un desequilibrio radical en el ejercicio del poder y de desdeñamiento a toda política de vinculación social entre géneros, perpetuando la desigualdad entre los devenires minoritarios y distribuyendo la violencia de forma misógina, homofóbica, (endo) racista, etc.

Desde nuestra perspectiva, Capitalismo Gore es el derramamiento de sangre explícito e injustificado (como precio a pagar por el Tercer Mundo que se aferra a seguir las lógicas del capitalismo como una forma de legitimidad y progreso), al altísimo porcentaje de vísceras y desmembramientos, frecuentemente, mezclados con el crimen organizado, el género y los usos predatorios de los cuerpos. Todo esto por medio de la violencia más radical como herramienta de necro-empoderamiento y reafirmación machista, ya que "un macho es un pobre al que sólo le quedan como recurso para hacerse notar la indiferencia ante la muerte propia o el dolor ajeno" (Monsiváis, 1990). El machismo exacerbado propuesto por el Estado ha devenido en agencia endriaga.

Usamos el término endriago para visibilizar que la perspectiva colonialista pervive en la construcción de narrativas teratológicas contemporáneas, donde las narrativas de lo colonial siguen vigentes en la

${ }_{13}$ De dificil acceso para sujetos pobres y racializados, quienes irónicamente conforman la mayoría de la población mundial. 
episteme g-local a través de múltiples factores como la economía y el endoracismo. Por tanto, el endriago sería la actualización del monstruo/Otro que da cuerpo y narrativa a los sujetos ultra violentos y demoledores del Capitalismo Gore: los sujetos endriagos.

El término endriago migra a nuestra taxonomía transfeminista desde la literatura medieval, específicamente del libro Amadís de Gaula. El endriago es un personaje literario medieval, un cruce de hombre, hidra y dragón, es decir, un monstruo. Es uno de los enemigos a los que se tiene que enfrentar el Amadís de Gaula ${ }^{14}$. Su fiereza es tal que la ínsula que habita se presenta como un paraje deshabitado, una especie de infierno terrenal al que solo podrán acceder caballeros cuya heroicidad rondara los límites de la locura y cuya descripción se asemeja a los territorios fronterizos contemporáneos ${ }^{15}$.

Además de las características adjudicadas al personaje literario, los sujetos endriagos contemporáneos tienen otras caracteristicas específicas y contextuales: surgen en el postfordismo, como consecuencia de la reconfiguración del concepto de trabajo y evidencian/ encarnan la vinculación entre la precariedad -a múltiples niveles- y la violencia fáctica, económica y simbólica.

Así, el contexto cotidiano de estos sujetos es:

[...] la yuxtaposición muy real de proliferación de mercancías y exclusión del consumo. [Son] contemporáneo[s] de la combinación de un número creciente de necesidades con la creciente falta de recursos casi básicos de una parte importante de la población. (Lipovetsky, 2007, p. 181)

De esta manera, los sujetos endriagos, -como receptores de las demandas tanto económicas como de género (masculino), de clase y de consumo vigentes- deciden hacer uso de la violencia como herramienta de necro-empoderamiento y de adquisición de capital.

\footnotetext{
14 Amadis de Gaula representaria al caballero y sus valores heredados a toda la cultura occidental. Amadís sería el sujeto occidental por antonomasia, el no monstruo, el no Otro, es decir, el sujeto universal y $\sin$ fisuras defendido por las lógicas del iluminismo y del humanismo.

15 Con territorios fronterizos nos referimos a las fronteras en general pero hacemos hincapié en las fronteras del norte de México que lindan con los Estados Unidos y que se ajustan perfectamente a lo descrito por ser ciudades actualmente copadas por los carteles de drogas, los traficantes de personas, la prostitución y las distintas fuerzas represivas del Estado, creando así un campo de batalla, es decir, un territorio en estado de sitio y militarizado.
} 
Con la conceptualización de la subjetividad endriaga tratamos de evidenciar que el uso de la violencia frontal se populariza cada vez más entre las poblaciones desvalidas como una herramienta de enriquecimiento rápida que puede hacer frente a la desvirilización que pende sobre muchos varones dada la creciente precarización laboral y su consiguiente incapacidad para erigirse de manera legitima en su papel de macho proveedor ${ }^{16}$. También resulta una estrategia eficaz para exorcizar la imagen y la condición de víctima y evitar ser leído como ilegitimo o minoritario por cuestión de clase o raza/etnia.

Pasando al tercer punto, consideramos necesario anotar el papel de los medios de comunicación en México, sobre todo el de la televisión y su influencia en el reforzamiento de un sistema cultural, ideológico y patriarcal. Nos referimos al uso truculento de su poder de difusión, que se visibiliza primero en la implantación y reproducción constante, aleccionadora, de modelos/coreografias de género que sirven para marcar "actitudes diferenciales y contrapuestas para cada género" (Valladares, 2007, p. 324) y que "a partir de ello el género masculino es sobrevalorado socialmente" (Valladares, 2007, p. 324), lo cual se traduce en asimetría entre las mujeres y los varones; y segundo (y ampliamente relacionado en sus consecuencias de asimetria), en su tratamiento efectista sobre la violencia criminal en todas sus variantes. Al mostrársela de forma repetitiva logra sobresaturarnos e inmunizarnos ante ella en gran medida.

El problema de la hipervisibilización de la violencia en México es que se le utiliza como un mecanismo de control y amedrentamiento sobre la población, al impedir así que la audiencia desarrolle un sentido crítico ante sus repercusiones reales y sus sesgos de género. De igual forma, se evita también la articulación de discursos, recursos y prácticas que no interpreten a la violencia solamente como un fenómeno externo y criminal -por tanto unidimensional, emparentado únicamente con la economía-, sino que logre desarrollar un sentido

\footnotetext{
${ }^{16}$ Es importante mencionar que algunas investigaciones sobre masculinidad afirman que "se ha ido perdiendo un modo legitimado de proveedor económico" (Lucioni, 2007, p. 343). Sin embargo, existe co-existencia en la interiorización y aplicación de viejos y nuevos discursos dentro de las prácticas de los varones y las demandas de masculinidad hegemónica (aunque reconocemos que estas son contextuales) han influido de forma contundente en la creación y propagación de la nueva clase criminal (integrada en su mayoría por varones) que disputa por hacerse con el poder absoluto del país. Un estudio reciente realizado por académicas de los centros de Investigaciones Interdisciplinarias en Ciencias y Humanidades (CEIICH) y Regional de Investigaciones Multidisciplinarias de la Universidad Nacional Autónoma de México, señala que la pérdida de empleo afecta el modelo hegemónico de masculinidad (un individuo proveedor, sexualmente disponible y con cierto grado de poder en algunos círculos). Se demuestra además, que perdido el poder económico se afecta la salud, así como la vida social y sexual de los varones. (Olivares Alonso, 2013).
} 
crítico a través de las transversales que se circunscriben a los géneros y que legitiman a los varones, como una de sus potestades masculinas, en el ejercicio de la violencia, tanto en el espacio público como en el espacio privado.

No obstante, esta hipervisibilización de la violencia criminal leída de forma crítica a través de herramientas desarrolladas por los transfeminismos, puede ayudarnos a crear conciencia en los varones acerca de la necesidad de un cambio radical en las estructuras del género; ya que funge de lupa magnificadora de las consecuencias que sufrimos todas y todos aquellos que, de alguna u otra forma, estamos siendo objeto de la violencia en la que se circunscribe México actualmente. Así, tanto la violencia criminal como la violencia machista ya no pueden ser vistas "a través de una bruma iridiscente, desodorizada, perfumada de hecho, con todas sus crueldades esenciales discretamente ocultas" (Wells, 1908, p. 81). Porque dicha violencia no es una práctica individual de la cual podamos des-adscribirnos o exculparnos fácilmente, sino que es un sistema de relaciones de poder y económicas que destruyen al tejido social y tarde o temprano nos terminan afectando a todos y todas porque, al ser sistémica, se vale de mecanismos de normalización y auto legitimación que necesitan de prácticas cada vez más atroces, para contrastar, confrontar y controlar el entorno social de lo normalizado.

\section{¿Cómo puede el transfeminismo redireccionar y proponer otros modelos para la creación de sujetos que no estén emparentados con la distopia gore, ni con la masculinidad hegemónica, ni con el hiperconsumismo neoliberalista?}

El narcotráfico, la criminalidad y la violencia espectacular han reconfigurado política, social y económicamente al México contemporáneo, tal como muestran diversos informes: Bourbaki (2011), Stratfor (2012), etc. Por ello, con esta reflexión hemos revisado brevemente las formas mediante las cuales las demandas de la masculinidad hegemónica emparentadas con la construcción y fortalecimiento de la idea de Estado-Nación y el capitalismo gore, como construcción económica y cultural, han contribuido a dicha reconfiguración.

Para esta última reflexión retomamos la perspectiva transfeminista, entendiéndola como una articulación tanto del pensamiento como de resistencia social, que es capaz de conservar como necesarios 
ciertos supuestos de las luchas feministas ${ }^{17}$, con el propósito de elaborar un acercamiento, crítico y localizado, que sirva de punto de partida para futuras articulaciones entre las resistencias no distópicas -que configuran el paisaje misceláneo de las ciudades del capitalismo gore (Valencia, 2010)- y temas relacionados con el uso subversivo de: el género, el lenguaje, la sexualidad, la etnia/raza, la diversidad funcional, la ecología, la economía y la política. Dichas resistencias no distópicas, representan una re-elaboración del tejido social en contraofensiva a las subjetividades endriagas del capitalismo gore.

Lo anterior nos conduce a la deseabilidad y pertinencia que supone la creación de otros sujetos políticos construidos desde el transfeminismo como marco epistemológico, abriendo de nuevo el debate sobre la necesidad y la vigencia del reto que implica que los sujetos masculinos se planteen otras configuraciones y condiciones bajo las cuales construir sus masculinidades para que sean capaces, no solo de ejecutarlas sino de crear un discurso de resistencia a través de ellas ${ }^{18}$.

Dicha construcción teórico-práctica debe tomar en cuenta las perspectivas transfeministas y el trabajo de deconstrucción antipatriarcal y anticolonial, así como las herramientas conceptuales que han creado los feminismos de colores, con el fin de replantear al sujeto femenino y descentrarlo a través de un desplazamiento hacia lo no hegemónico, ni predeterminado por la biología.

Como lucidamente enunciaba Simone de Beauvoir -hace más de medio siglo- "no nacemos mujeres, sino que devenimos en ello" (1981, p. 13), es hora de pasar la pregunta hacia el campo de la masculinidad para descentrarla y hacer construcciones de esta más aterrizadas en la realidad, cuyos resultados desemboquen en la encarnación de las masculinidades singulares que comprueben que tampoco se nace hombre sino que se puede devenir en ello a través de procesos, en todo

${ }^{17}$ Cuestiones referentes a la autogestión de los cuerpos femeninos, masculinos, trans y diversos funcionales así como el ejercicio libre de una sexualidad no señalada por reglas morales y/o religiosas que inciten al racismo, la homofobia, lesbofobia, transfobia o prohibición del trabajo sexual.

18 Ponemos de relieve que nos referimos especialmente a la revisión de la masculinidad incorporada en las realidades latinoamericanas y sobre todo, no obviamos el hecho de que existen ya algunas formas de confrontación de esta masculinidad en esos espacios que no comparten ni obedecen a los dictados del poder capitalista y machista y han logrado desanudarse, en la medida de lo posible y de forma crítica, de la identidad dominante. Ejemplos de esto los encontramos en Argentina con el grupo de varones anti-patriarcales que se autodenominan: Ni machos ni Fachos (s.f.) y en México en El Movimiento de Hombres por Relaciones Equitativas y Sin Violencia (MHORESVI, s.f.), fundado en 2006 . 
momento modificables, que están íntimamente vinculados con el contexto y con la economía.

La vigencia de este replanteamiento de la Masculinidad en masculinidades plurales y localizadas que detenten una perspectiva crítica sobre los efectos de la economía en la distribución de vulnerabilidad en el tercer mundo g-local se justifica en el hecho de que en la práctica estas nuevas masculinidades ya subsisten y hacen resistencia a la masculinidad hegemónica y a sus violencias, creando un punto de intersección entre el devenir minoritario al que se enfrentan los varones contemporáneos por causa de la precariedad económica-que desmantela aceleradamente su sistema de privilegios de género- y otros devenires minoritarios que por cuestiones de género, raza/etnia, disidencia sexual, etc., han estado relegados del sistema de privilegios heteropatriacales y racistas. En este encuentro entre subjetividades se crea un espacio de confluencia en donde se muestran de forma explícita las formas en que el capitalismo ha instituido sistemas basados en el binarismo de género como formas de organizar la labor (re)productiva en contextos coloniales y cómo estos sistemas están mutando actualmente con el fin de otorgar privilegios solo a aquellos cuerpos que sean productivos, es decir rentables para el capitalismo.

Por tanto, es a través de la elaboración y visibilización de un discurso autocrítico -hecho por los mismos varones y en diálogo con los transfeminismos hacia las relaciones de poder- que se puede dar una modificación real en las prácticas cotidianas de las masculinidades. Preparando así un terreno propicio para la elaboración de nuevos modos de comportamiento que alejen a los varones de la masculinidad hegemónica (Connell, 2010) y su sistema de órdenes y contraordenes cuya obediencia ciega conduce a la violencia machista y la reproducción de la perspectiva colonial.

Un ejemplo de este distanciamiento autocrítico lo encontramos en la agenda de los hombres por la igualdad, redactada en Barcelona en el marco del Congreso Iberoamericano de Masculinidades y Equidad (CIME, 2011) y de la cual reproducimos sus cinco primeros puntos:

1. Rechazamos el ejercicio del poder patriarcal y renunciamos a los privilegios que de él se derivan.

2. Denunciamos todas las formas de violencia machista hacia las mujeres, fomentando la revisión crítica del sexismo interiorizado y desarrollando un trabajo de sensibilización y prevención de esta 
violencia entre los hombres; apostando por la defensa de los Derechos Humanos y la resolución pacífica de los conflictos.

3. Asimismo rechazamos otras violencias machistas (bullying, homofobia, transfobia).

4. Promovemos la corresponsabilidad de los hombres y los cuidados compartidos, con especial referencia a la responsabilidad de los hombres en nuestro propio cuidado y el de las personas dependientes y mayores, apoyando medidas de conciliación de la vida laboral y personal.

5. Impulsamos la paternidad activa y responsable, fomentando la implicación de los padres y la mejora de las habilidades para la crianza, siendo incluidos en los cursos de preparación al parto, primeros cuidados y cuidado de la madre. En este sentido, reivindicamos que los permisos de maternidad y de paternidad sean iguales, intransferibles y pagados a cargo de la Seguridad Social al 100\% del salario. (CIME, 2011).

La cita anterior nos muestra que existen muchos sujetos masculinos que quieren, buscan y necesitan deslindarse de los patrones arcaicos y opresores de la masculinidad tradicional y que incitan a ese cambio porque reconocen que eso es lo más favorable para todos y todas. Pero para que esta reconfiguración de las masculinidades sea posible y tenga incidencia en la reelaboración del tejido social de México contemporáneo, es necesario que el modelo de aspiraciones sobre la masculinidad cambie. Dicho cambio debe ser colectivo, ya que aunque la masculinidad sea un modelo que determina la vida y la conducta personal, sus consecuencias no lo son, pues retroalimentan modelos de socialización emparentados con la historia mundial y la globalización, es decir que se perfilan con gran influencia de las luchas geopolíticas, del imperialismo y del colonialismo.

Por ello, la transformación de la masculinidad en México actual debe ser una tarea primordial que debe reflejarse a varias escalas en el terreno de las instituciones (con una crítica radical del machismo estatal), en el terreno de la cultura (con una educación no sexista) y en el de la comunidad (con unas prácticas de género que superen los prejuicios en torno a ello, para romper las visiones desarticulantes y de enfrentamiento que socialmente se les han otorgado). 
Por otro lado, la importancia en la deconstrucción del modelo de masculinidad machista también está claramente ligada a otra, a la de deconstruir el falogocentrismo patriarcal que emparenta directamente al capitalismo gore como un continuum contemporáneo del colonialismo. De tal forma que la creación de nuevos discursos sobre las masculinidades disidentes, puede añadir y complementar una visión crítica del papel de los sujetos endriagos del Capitalismo Gore.

Estos sujetos distópicos, violentos y feroces pueden ser leídos como la encarnación de una masculinidad obediente a las demandas de género masculino y como una actualización in extremis de la lógica colonial, la cual:

[...] identificó a los hombres colonizados con el cuerpo y los definió como violentos y estúpidos, mientras que a los hombres de las elites los consideró inteligentes y moralmente virtuosos. [...] Así, las imágenes de la masculinidad se entretejieron con la creación de jerarquías raciales que aún persisten. (Conell, 2006, p. 195)

Imágenes que se recrean en un modelo de masculinidad autoritaria, agresiva, heterosexual, valiente con cuerpos capaces de desafiar, a la cual se respeta más que a las demás. Es a dicho modelo al que pretende acceder la subjetividad endriaga.

Este modelo de masculinidad violenta emparentada con el Estado no es un caso aislado en México, sino de producción y reproducción de ciertos rasgos de género que se repiten en los países ex coloniales y se relaciona con la identidad nacional, creando en palabras de Connell, "un orden de género mundial" (Connell, 2006, p. 188) el cual puede definirse como "la estructura de relaciones que a escala mundial, conecta a los regímenes de género de las instituciones con las ordenes de género de las sociedades locales."(Connell, 2006, p. 188). Este orden de género es el resultado de la sociedad global, la cual distribuye a través de dispositivos culturales y tecnologías de género (De Lauretis, 1989), unos ideales de aspiraciones tanto de masculinidad como de feminidad, que estandarizan a todo el mundo -ideales que son consumidos por las sociedades g-locales-. 
Por ello, es necesario que la deconstrucción de la Masculinidad y la creación de un plural de la misma ocurra de la mano con la perspectiva de género y el transfeminismo, entendiéndolo no solo como un movimiento social de y para las mujeres, sino como una categoría epistemológica para la comprensión y creación de nuevos agenciamientos (más allá de los géneros, pero sin invisibilizar sus luchas) no distópicos ${ }^{19}$.

Además, es necesario evitar anclarnos en presupuestos de género dicotómicos y jerárquicos para la construcción de estas nuevas alianzas intersubjetivas, dado que lo que sabemos de los géneros tiende a caer en la tentación del solipsismo de construir la identidad del otro a partir de clichés y estereotipos que, si bien tienen una base real, contienen el peligro de ser incompletos, o bien desde proyecciones de la propia identidad.

El trabajo de defender una identidad inamovible nos desvía de encontrar las intersecciones perversas entre el capitalismo y la biopolítca, que históricamente ha gestionado los cuerpos de las poblaciones por medio de la invención y defensa de ficciones políticas basadas en esencialismos corporales como: raza, género, sexualidad heterosexual, integridad corporal. Modelando y legitimando así a los sujetos según las necesidades (re)productivas del sistema económico imperante.

Encontramos sumamente importante como estrategia, el hecho de que los varones al deconstruirse y reinventarse busquen espacios para sí, fuera de los límites fijados por la heteropatriarquía y la violencia como herramienta de autoafirmación viril. A este respecto, lo deseable es que las masculinidades contemporáneas sean capaces de desobedecer y estafar al patriarcado al renunciar a sus dividendos de género.Algunas estafas prácticas al patriarcado radicarian, por un lado, en el ejercicio de una paternidad activa en el cuidado y la educación de los hijos, ya que desactivaría desde la agencia individual, los mandatos de género que han confinado las relaciones entre los padres y las y los hijos a una relación emocionalmente precaria y de distanciamiento físico.

Por otro lado, estaría la implantación de un modelo de (re)educación no sexista que se desarrollara desde los primeros años de las y los niños y que desvinculara los presupuestos de género que se basan

\footnotetext{
${ }^{19}$ Perteneciente al término Distopía y acuñado, según datos del Oxford English Dictionary, a finales del siglo XIX por John Stuart Mill que lo utilizó como antónimo a la Utopía de Thomas Moro y con el cual buscó designar una utopía negativa donde la realidad transcurre en términos antitéticos a los de una sociedad ideal (OED, s.f.)
} 
en la asimetria, dando espacio para que las y los niños construyan sus posicionamientos de género de una manera más liberadora, autónoma y fluida, menos jerárquica y sobre todo, educándolos para reivindicar su derecho a la diferencia. También resultara preciso desestigmatizar los modelos de conducta de los colectivos LGTTTBIQ ${ }^{20}$ y revisar los logros en la reinvención de la subjetividad que el movimiento queer/ cuir ha proporcionado y que puede proveer una relectura interseccional de las subjetividades. Es importante reconocer que las prácticas del movimiento queer/cuir han sido una resistencia pública, pacífica y eficaz, cuyas reivindicaciones no se anclan solamente en las preferencias sexuales ni en un esencialismo biologicista -ya que niegan toda esencia por considerarla reaccionaria y opresora.

Estas resistencias nos muestran que son conscientes de que "innumerables procesos de minorización están atravesados por la sociedad" (Guattari y Rolnik, 2006, p. 94) pero también que estos a su vez atraviesan a la sociedad, haciendo de la biopolitica un proceso reversible y que frente a la violencia fisica y la opresión recalcitrante utilizada por el sistema heteropatriarcal, hegemónico y conservadurista -representado en la actualidad por el capitalismo gore-, la desobediencia ante ello y la ingobernabilidad pueden venir de las vías menos consideradas por la legitimidad social.

El movimiento queer/cuir no apela a la normalización como sinónimo de legitimidad. Esto nos muestra que frente al monopolio de la violencia legítima e ilegítima existen frentes de resistencia que pueden entremezclar su agencia con una visión de activismo lúdico-crítico y anticapitalista, sin que esto deba entenderse de forma abstracta o superficial, dado que implica una autocrítica y una revisión reflexiva con respecto al papel de las resistencias queer/cuir y transfeminista frente a las identidades de género y frente al consumismo:

El consumo también condiciona nuestros cuerpos, determinando su forma, atravesando nuestra identidad y exigiendo que nuestros afectos se inscriban dentro de una marca registrada. No queremos habitar un ghetto comercial donde sólo se existe siendo un gay-trans-lesbiana de fin de semana. Donde las relaciones se mercantilizan y solo se tiene acceso a este supuesto "existir" a través del dinero. No queremos consumir para finalmente ser consumidos por el mismo engranaje que nos oprime. (Manifiesto Con fronteras no hay orgullo, 2009)

\footnotetext{
${ }^{20}$ Lesbianas, Gays, Bisexuales, Transexuales, Transgéneros, Travestis, Intersexuales y Queer.
} 
El modelo transfeminista representa una deconstrucción del pensamiento heteropatriarcal-sexista pues es el resultado de luchas y reflexiones interseccionales. Supone esto una ruptura y a la vez un continuum con la tradición feminista, lo cual supone un giro performativo en la interpretación de la identidad. Por supuesto, no es la panacea, pero nos da referentes de que hay otras posibilidades interpretativas y de construcción/deconstrucción de la subjetividad que retan a las rígidas estructuras de los géneros, los sexos y el discurso colonial.

Así las cosas, las masculinidades no podrán ser entendidas como nuevas si se desligan del transfeminismo y del movimiento queer y si no logran desligarse de la obediencia y la investidura de la masculinidad como la entienden el poder y el discurso hegemónico. Es decir, la reconfiguración de estas nuevas masculinidades, como una forma de fraguar subjetividades no distópicas debe estar emparentada con la resistencia, pero desde un espacio que no las vincule con la ejecución del poder de forma vertical y heteropatriarcal, lo cual nos lleva directamente al problema del replanteamiento del concepto y el ejercicio de la política bajo estas condiciones del devenir queer/cuir que no se circunscribe solamente a prácticas homosexuales sino que implica "una posición de crítica atenta a los procesos de exclusión y de marginalización que genera toda ficción identitaria" (Preciado, 2009). Se trata pues, del desarrollo de una cuiradanía que repiensa y reactiva agenciamientos desde los devenires minoritarios y la perspectiva descolonialista ${ }^{21}$.

Desde nuestra perspectiva transfeminista, la forma en que entendemos la politica debe cambiar y su práctica debe ser reescrita bajo las variables de los devenires minoritarios que busquen alianzas posibles para la construcción de comunes $^{22}$ y no tanto de perpetuar las lógicas de reconstrucción del tejido social, ya que dicho tejido está atrave-

${ }^{21}$ Esta perspectiva descolonial no apela a una posición de indolencia intelectual sino a lo que Nelson Maldonado Torres dice respecto a la actitud des-colonial: "[...] nace cuando el grito de espanto ante el horror de la colonialidad se traduce en una postura crítica ante el mundo de la muerte colonial y en una búsqueda por la afirmación de la vida de aquellos que son más afectados por el mundo. Estamos hablando pues de una transición del horror a lo que se podría llamar, siguiendo la pista de la teórica chicana Chela Sandoval, como amor des-colonial (2000). El surgimiento de la actitud des-colonial envuelve pues un estado afectivo que le es fundamental, a la vez que puede considerarse, tal como lo hace claro el afro-caribeño Frantz Fanon en su Piel negra, máscaras blancas (1973) en principio, de un tipo particular de filosofia y producción teórica." (Maldonado Torres, 2008, pp. 66-67)

22 "[...] Cabría decir que lo "común" de la multitud no habrá de buscarlo en el más pequeño denominador común que se da naturalmente, como la esencia común del explotación; lo común es el objeto mismo que hay que construir políticamente, aceptando medirse con la simultaneidad de las opresiones. No el poder de "gobernar a los otros" sino el poder para construir en común y de forma compartida, los espacios en los que habitamos” (Galcerán, 2009, p. 198). 
sado por lógicas terriblemente reaccionarias y conservadoras que de reconstruirse, seguirán propagando los mismos modelos de interpretación/acción respecto al género, sexualidad, clase, raza y poder.

En este espacio de crisis y violencia generalizada en México, la propuesta desde el transfeminismo es que el agenciamiento y la construcción de relaciones sociales no sean entendidas ya como el arte de gobernar a los otros sino como la redistribución de estrategias de supervivencia para hacer crecer lo común.

En estos tiempos de crisis civilizatoria la figura de la(s) mujer(es) puede leerse como un enclave doble. Por un lado, se desdibuja por la proliferación de imágenes-mercancía que la reinsertan en las lógicas predatorias del consumo y la rentabilización. Sin embargo, dentro de estas mismas lógicas de sobre representación/invisibilización, la metáfora de mujer(es) también se actualiza de manera disidente y radical: en el devenir minoritario de los varones por causas económicas. Es decir, se actualiza en ese devenir mujer de los varones, que pueden ser representados por esa misma metáfora, donde la(s) mujer(es) ya no es (no somos) solamente una entidad biológicamente situada, ni un ente aislado, explotable, vulnerable y destruible, sino la representación de una opresión histórica e interseccional que ha logrado desobedecer al género y desarrollar estrategias de superviviencia frente a sus demandas predatorias. Que ha logrado, además, agenciarse pacíficamente visibilizando la simultaneidad de las opresiones. Por eso, en nuestros prototipos comunes como en nuestras disimetrías, consideramos que es necesario el descentramiento de la categoría de Masculinidad (Halberstam, 2008) entendida como una propiedad intrínseca y exclusiva del cuerpo de los varones.

Este descentramiento llevaria a una reconstrucción discursiva no abyecta que cuente con capacidad de multiplicar las posibilidades en el abanico de la construcción de nuevas subjetividades tanto para las mujeres como para los varones -incluyéndose en estas nuevas categorizaciones tanto a las bio-mujeres, bio-hombres así como a las tecnomujeres, tecno-hombres y personas intersex- creando un marco que ensanche nuestras posibilidades de acción y reconocimiento.

El desplazamiento des-esencializante de las categorias y potestades de la masculinidad supondría un cambio epistemológico y discursivo sin precedentes en la construcción de nuevas masculinidades y feminidades, que se reflejaria en las relaciones sociales en todas sus escalas, haciendo posible la tarea de re-elaborar -y no tanto de reconstruir- el tejido social en nuestro contexto mexicano, puesto que 
el primer término parte de la perspectiva transfeminista que tiene la intención de separarse de elementos biologicistas, identitarios o nacionalistas por considerarlos profundamente reaccionarios -aun siendo usados por movimientos progresistas- y se propone a favor de dinamitar la ortodoxia de lo que puede ser considerado actualmente como agenciamiento político.

Por supuesto, esta reflexión es solo un punto de partida modesto para futuras elaboraciones respecto al problema de violencia estructural acontecida en el territorio mexicano, una explicación interseccional que busca visibilizar ciertas conexiones entre la construcción estatal y sexista del género y la ruptura del tejido social en México contemporáneo.

\section{Referencias}

Beauvoir, S. (1981). El segundo sexo. II. La experiencia vivida. Buenos Aires: La Pléyade.

Bourbaki (2011). El costo humano de la guerra por la construcción del monopolio del narcotráfico en México (2008-2009). México. [Versión electrónica]. Disponible en: http://laredmm.files.wordpress.com/2011/08/informebourbakilowres2def.pdf

CIME (2011). La agenda de los hombres por la igualdad. octubre 82011 , Barcelona. Disponible en: http://www.ahige.org/pdfs/DECLARACION_DE_ BARCELONA.pdf

Connell, R. W. (2006). Desarrollo, globalización y masculinidades. En Careaga, G. y Salvador Cruz. Debates sobre masculinidades. Poder, desarrollo, politicas públicas y ciudadanía (pp.185-210). México: UNAM/PUEG.

Connell, R. W. (2010). Masculinidades. México: UNAM.

Courvant, D., y Koyama E. (2000). Transfeminist Anthology Project, transfeminism. org. Disponible en: http://web.archive.org/web/20000816213525/http://www. transfeminism.org/

Davis, M. (2008). Ciudades muertas. Ecología, catástrofe y revuelta. Madrid: Traficantes de Sueños.

De Lauretis, (1989). Technologies of Gender. Essays on Theory, Film and Fiction. London: Macmillan Press.

Fanon, F. (1973). Piel negra, máscaras blancas. Buenos Aires: Abraxas.

Galcerán, M. (2009). Deseo (y) Libertad. Una investigación sobre los presupuestos de la acción colectiva. Madrid: Traficantes de Sueños. 
Guattari, F. y Rolnik, S. (2006). Micropolitica. Cartografias del deseo. Madrid: Traficantes de Sueños.

Halberstam, J. (2008). Masculinidad Femenina. Madrid: Egales.

Hill, R. J., (Report Chair), Childers, J., Childs, A. P., Cowie, G., Hatton, A., Lewis, J. B., McNair, N., Oswalt, S., Perez, R. M. y Valentine, T. (2002). In the shadows of the arch: Safety and acceptance of lesbian, gay, bisexual, transgendered and Queer students at the University of Georgia. Athens, Georgia: Department of Adult Education.

Lewis, O. (1959). Cinco Familias. Mexican Case Studies In The Culture Of Poverty. New York: Basic Books.

Lewis, O. (1961). The children of Sanchez, Autobiography Of A mexican family. ( $4^{\mathrm{a}}$ ed.) Gotinga: Lamuv-Verl.

Lipovetsky, G. (2007). La felicidad paradójica. Ensayo sobre la sociedad hiperconsumista. Barcelona: Anagrama.

Lucioni, M. (2007). Pensar la violencia en los contextos de la vida. En M. L. Jiménez y O. Tena Guerrero (Coords.). Reflexiones sobre masculinidades y empleo (pp. 339-356). Cuernavaca: UNAM, Centro Regional de Investigaciones Multidisciplinarias.

Maldonado Torres, N. (2008, julio-diciembre). La descolonización y el giro descolonial. Revista Tabula Rasa, (09), 61-72.

Manifiesto Con fronteras no hay orgullo: Lesbianas, Gays, Trans, Bisex, Queer y Heteros contra la ley de extranjería y la represión a lxs inmigrantes. (2009, junio 27). Madrid. Disponible en: http://confronterasnohayorgullo.blogspot.com/

Monsiváis, C. (1981, abril-mayo). ¿Pero hubo alguna vez once mil machos?. FEM, (18), 9-20.

Monsiváis, C. (1990, septiembre-octubre). Control y condón. La revolución sexual mexicana. Nueva Sociedad, (119), 99-105.

Montesinos, R. (2004, julio-agosto). Los cambios de la masculinidad como expresión de la transición social. El Cotidiano, 20 (126), 1-16.

Moraga, C. (1988) La Güera. En C. Moraga y A. Castillo (Comps.). Este puente, mi espalda. Voces de mujeres tercermundistas de los Estados Unidos (pp.19-33). San Francisco: Ism Press.

Movimiento de Hombres por Relaciones Equitativas y Sin Violencia (MHORESVI). (s.f.). Recuperado de http://mhoresvi.wordpress.com/)

Ni machos ni Fachos. (s.f.). Disponible en: http://colectivovaronesantipatriarcales. blogspot.mx/

Olivares Alonso, E. (2013, julio 4). Un hombre desempleado rompe el modelo de masculinidad impuesto, revela estudio. Periódico La Jornada. Disponible en: http://www.jornada.unam.mx/2013/07/03/sociedad/040n1soc). 
Oxford English Dictionary (OED). (s.f.). Oxford English Dictionary. Disponible en http://www.oed.com

Preciado, B. (2009, mayo). Transfeminismos y micropolíticas del género en la era farmacopornográfica. Revista ARTECONTEXTO, (21), 58-61.

Revista Ramón (2010, abril). Dossier Micropoliticas Cuir: Transmariconizando el Sur. Delfino, S., Rapisardi, F., Vásquez, E., Carbajal, F., Preciado, B., Guerrero, I., Mujeres Públicas, Campuzano, G., López, M., León de la Barra, P., Rivas San Martín, F., Fuenzalida, E., Galindo, M., Mujeres Creando y Rodríguez, V.M. Davis. F. y M. A. López (Eds. Invitados). .Disponible en: http://es.scribd.com/ doc/31922861/ramon-99-revista-ramona-de-argentina

Sandoval, C. (2000). Methodology of the oppressed. Minnesota: University of Minnesota Press.

Stratfor. (2012, enero 24). The polarization and sustained violence in Mexico's cartel war. Agencia Stratford. Disponible en: http:/ /www.stratfor.com/sample/ analysis / polarization-and-sustained-violence-mexicos-cartel-war

Valencia, S. (2010). Capitalismo Gore. Barcelona: Melusina.

Valladares, P. (2007). Desempleo y violencia masculina. En M. L., Jiménez y O., Tena Guerrero (Coords.). Reflexiones sobre masculinidades y empleo (pp. 327-338). Cuernavaca, México: UNAM, Centro Regional de Investigaciones Multidisciplinarias.

Villaplana, V. (2008). Zona de intensidades. Madrid: Aconcagua Publish.

Wells, H. G. (1908). The War in the Air. Gran Bretaña: Pall Mall Magazine.

Zapata, G. M. (2001). Más allá del machismo. La construcción de masculinidades. En H. Silke, (Ed.) y M. Sandoval (Trad.). Género, feminismo y masculinidad en América Latina (pp. 225-247). El Salvador: Editorial Heinrich Böll, S.I.

Ziga, I. (2009). Devenir Perra. Barcelona: Editorial Melusina.

\section{Cómo citar este artículo}

Valencia, S. (2014). Teoría transfeminista para el análisis de la violencia machista y la reconstrucción no-violenta del tejido social en el México contemporáneo. Universitas Humanistica, 78, 66-88. http://dx.doi.org/10.11144/Javeriana. UH78.ttpa 